\title{
Classification of Crop Lands over Northern Mongolia Using Multi-Temporal Landsat TM Data
}

\author{
Gerelmaa Ganbaatar and Kyu-Sung Lee
}

Inha University, Department of Geoinformatic Engineering, Incheon, Korea

\begin{abstract}
Although the need of crop production has increased in Mongolia, crop cultivation is very limited because of the harsh climatic and topographic conditions. Crop lands are sparsely distributed with relatively small sizes and, therefore, it is difficult to survey the exact area of crop lands. The study aimed to find an easy and effective way of accurate classification to map crop lands in Mongolia using satellite images. To classify the crop lands over the study area in northern Mongolia, four classifications were carried out by using 1) Thematic Mapper (TM) image August 23, 2) TM image of July 6, 3) combined 12 bands of TM images of July and August, and 4) both TM images of July and August by layered classification. Wheat and potato are the major crop types and they show relatively high variation in crop conditions between July and August. On the other hands, other land cover types (forest, riparian vegetation, grassland, water and bare soil) do not show such difference between July and August. The results of four classifications clearly show that the use of multitemporal images is essential to accurately classify the crop lands. The layered classification method, in which each class is separated by a subset of TM images, shows the highest classification accuracy (93.7\%) of the crop lands. The classification accuracies are lower when we use only a single TM image of either July or August. Because of the different planting practice of potato and the growth condition of wheat, the spectral characteristics of potato and wheat cannot be fully separated from other cover types with TM image of either July or August. Further refinements on the spatial characteristics of existing crop lands may enhance the crop mapping method in Mongolia.
\end{abstract}

Key Words : crop classification, Mongolia, TM, multi-temporal images

\section{INTRODUCTION}

Although agriculture plays an important role in Mongolia's economy by contributing 21.7 percent to Gross Domestic Product (GDP) and employing 40 percent of the labor force (FAO, 2011), most agriculture areas are natural pasture for livestock breeding and include very small area of crop land. It is known that the size of crop land is less than $1 \%$ of the country's total area of $1,560,000 \mathrm{~km}^{2}$. Agricultural statistics on crop land is not reliable because of the difficulty to survey crop land over the nation. Crop cultivations are

Received December 3, 2013; Revised December 11, 2013; Accepted December 16, 2013.

$\dagger$ Corresponding Author: Kyu-Sung Lee (ksung@inha.ac.kr)

This is an Open-Access article distributed under the terms of the Creative Commons Attribution Non-Commercial License (http://creativecommons. org/licenses/by-nc/3.0) which permits unrestricted non-commercial use, distribution, and reproduction in any medium, provided the original work is properly cited 
carried out on sparsely distributed small land parcels. Further, permanent crop lands are relatively rare because of the limitations in climate, topographic, and soil conditions. Crop lands are often abandoned or left as fallow ground after a few years of cultivation.

Crop production in Mongolia has slowly increased to supply domestic consumption. In recent years, there has been relatively large scale conversion of grassland to crop land for the cultivation of crops and vegetables. However, the converted crop lands had not been properly cultivated due to the lack of necessary farming skills and the limitation of soil and climate conditions. Such crop lands had been eventually abandoned and can be a problem of land degradation and desertification (Batbileg, 2009). Improper conversion of grassland to crop land could affect environmental changes ranging from desertification and soil erosion (Lanjeri et al., 2001) to soil carbon loss (Wilhelm et al., 2011).

The Mongolia government has started a program to establish sustainable development plan on natural resources and to increase arable crop lands (UNDP, 2012). One of the key issues on the plan is to have reliable statistics on land use and land cover. Major agricultural crops, wheat and potato, are grown sporadically in relatively small pieces of land. Therefore, it is very difficult to get information on exact size and location of the crop lands. The national agricultural and land management agencies want to find an easy and effective way of surveying crop lands and obtaining crop yields estimates. Although local municipalities had surveyed crop land and yield estimation, their statistics were known to have significant errors. Furthermore, the field-based survey takes a great amount of time and effort. Considering the situation of the Mongolia's crop lands, remote sensing can be an alternative to provide consistent and accurate crop inventory data across the scale of province and the nation.

Satellite remote sensing images have been widely used for crop monitoring and mapping since 1970's,
With the first launch of Landsat-1, Multispectral Scanner (MSS) images were used for crop inventory through the Large Area Crop Inventory Experiment (LACIE) and the Agricultural Resources Inventories through Aerospace Remote Sensing (AgRISTARS) program (Ortiz et al., 1997). Satellite images have provided information on crop type, condition, area and growth stages (Turker and Arikan, 2005). In remote sensing based crop inventories, it was found that the spectral characteristics of crop were different by growing stage and, therefore, it may not be possible to detect diverse crop status in a single image (Murthy et al., 2003). By incorporating the temporal variation of crop type and condition, multi-temporal images have shown great improvement in crop mapping and inventory studies (Conese and Maselli, 1991; Murthy et al., 2003; Lay, 2005; Maruthi Sridhar et al., 2010; Jang et al., 2012). Mulla (2012) reviewed that temporal frequency of remote sensing data was an important factor in agricultural applications. Multi-temporal images were also known to be effective for land cover classification (Jeong et al., 2006) and for land cover change monitoring over arid region (Ryu et al., 2013).

In a conventional supervised classification of multispectral images, all classes must be defined and trained in detail (Foody and Mathur, 2006). The classification of multi-temporal images often requires other approaches than conventional maximum likelihood classification technique. Turker and Arikan (2005) showed that the sequential classification would be better for crop mapping if additional images were used for crop mapping. In this study, we are trying to find an effective and accurate method to map sparsely distributed crop lands in Mongolia using satellite images. Accurate crop land inventory is an essential requirement for the crop yield estimation and the regional and national land planning for the sustainable development. 


\section{STUDY AREA AND DATA USED}

The study area, the Bornuur County is a sub-region within the Tuw Province in northern Mongolia and is located about $100 \mathrm{~km}$ north from the capital city, Ulaanbaatar (Fig. 1). From the Mongolia national statistics of 2011, this region has 118ha of cultivated crop lands. The study area has about 5,000 populations and has been used for crop lands since 1970. Beside the crop lands, other land cover types include forest, bare soil, grassland, and riparian vegetation along the seasonal stream. The study area has average elevation of 705 meters above mean sea level and has hilly and mountainous topography. There is relatively large stream (the Kharaa River) passing through the study area and riparian vegetation is developed along the stream.

This area has an extreme continental climate with a long cold winter and a short hot summer. The temperatures vary greatly throughout the year. The hot summer season is from June to August with average temperature ranges from $30^{\circ} \mathrm{C}$ to $43^{\circ} \mathrm{C}$. The mean annual precipitation over the last twenty years was $280 \mathrm{~mm}$, in which most rainfall comes during the growing season from May to September. Because of the short summer season and the lack of precipitation, crop cultivation in this region has been very limited. Wheat and potato are major crop types in this area. Irrigation farming system is expanding in Mongolia, although it is available for very limited area. In this region, small crop lands along the Kharaa River were partially irrigated during the growing season.

For the classification of crop lands in the study area, we used Landsat 5 Thematic Mapper (TM) images obtained on July 6 and August 23, 2010. Two TM images were selected as to incorporate the crop phenology of wheat and potato over the area. Among seven TM bands, we used six reflective bands excluding the termal infrared band. In addition to the TM images, 1:50,000 topographic maps and the land use map including adminstrative boundary were also obtained from local government agencies for reference.

\section{METHODS}

\section{1) Crop Phenology of Wheat and Potato}

Because of the climate condition over the study area, the growing season is relatively short. In general, the plantation begins in late April and the harvest time is

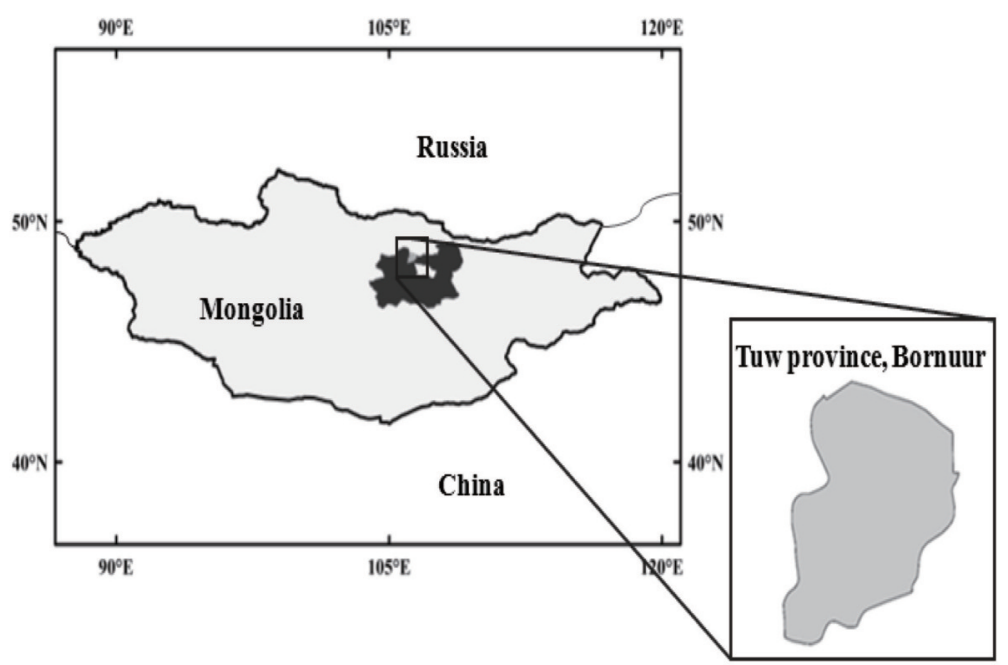

Fig.1. Location of the study area in northern Mongolia. 


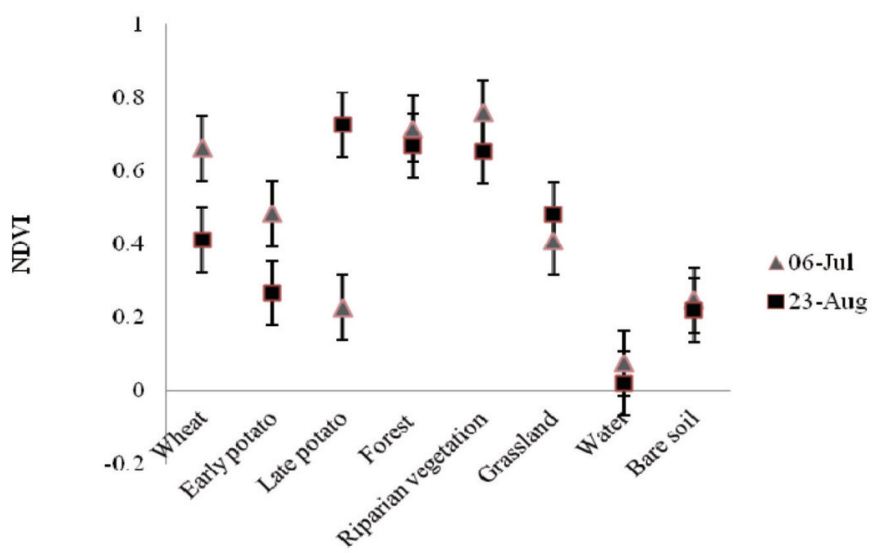

Fig.2. Comparison NDVI between early July and late August for wheat, potatoes, and other cover types.

middle of September. However, exact time of plantation and harvest varies by crop type and soil moisture condition. Wheat needs at least 110 days of growing season between sowing and harvest. In the study area, the sowing of wheat begins in late April and the harvest time is usually early September. On the other hand, potato cultivation requires less growing days than wheat. The potato planting time varies by field condition of soil moisture, climate, and type of seed. The actual time of potato planting in the area differs by more than a month. The early potato is planted in April and harvested in July, while the late potato is planted in May and harvested in late August. Although the main interest of the study is to classify wheat and potato fields, there are other land cover types that are spectrally similar to the crop lands.

Fig. 2 compares NDVI values of wheat and potato as well as other land covers, which were observed from the two TM images in the study area. The early potato, planted in April, shows sufficient leaf growth with relatively high NDVI in July image, while its NDVI drops quickly in August when the early potato reaches senescence stage or may have been harvested already. The late potato, planted in May, is still in very early growing stage with low NDVI in July, while makes it difficult to separate it from surrounding bare soil. The late potato reaches the maximum leaf growth in August image, which shows similar NDVI values with other vegetation cover types. Wheat also shows temporal variation between two observation times in early July and late August, while other land cover types show similar spectral characteristics between two times. Therefore, it would be essential to use two different TM images to separate crop lands from other land cover types.

\section{2) Classification for Crop Mapping}

We used two classification schemes to delineate wheat and potato fields using multi-temporal TM images. The first scheme is a standard maximum likelihood classification on the combined 12 bands of two TM images of July and August. This classification method has been widely adopted for multitemporal image classification by using temporal characteristics of different crop phenology (Lay, 2005). As seen in Fig. 2 , the two crop types show large spectral variation between early July and late August while the other cover types (forest, riparian vegetation, grassland, water and bare soil) do not show such difference.

The second classification scheme used is similar to the layered classification method, in which each class is separated by a subset of multi-band image. The layered classification process is shown in Fig. 3. First classification was performed on the TM image of 


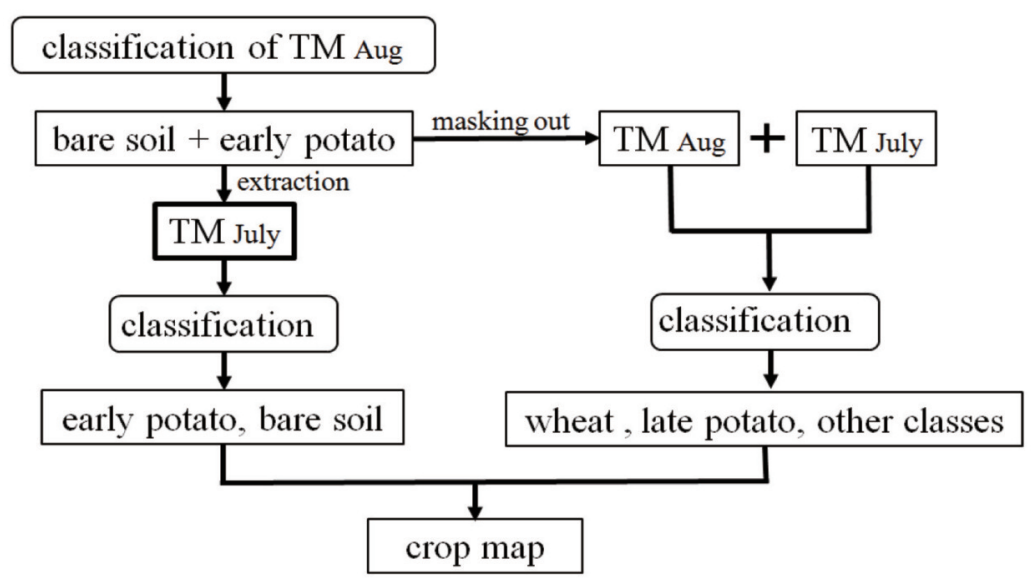

Fig. 3. Layered classification process to classify wheat and potatoes using two multitemporal TM images.

August to extract bare soil class. Since the early potato has been almost harvested in August, the bare soil class also includes the early potato fields. The second classification was applied on the combined July and August TM data after the bare soil (and early potato) areas were masked out from the August TM image. From the second classification, we were able to classify the wheat and late potato fields as well as other land cover classes. The third classification was performed on TM image of July for the area corresponding to the only bare soil (and early potato) class that had been extracted by the first classification. Although the early potato has similar spectral characteristics with bare soil in August, it is clearly different from bare soil in July because of the sufficient leaf growth at that time.

We have selected enough numbers of training samples for the eight classes of wheat, early potato, late potato, and other cover types. To select training pixels, we initially used the Irrigation Map obtained from the local land planning agency. We further verified the ground truth information by the field survey over the study area, which were carried out during the summer of 2013. During the field survey, it was found that most bare soil lands were either abandoned or fallow ground for crop rotation due to the low soil fertility. Test samples were also collected each of eight classes including both early and late potatoes to assess the classification accuracy. Among the 1,194 test pixels, 511 pixels were collected from wheat, early potato, and late potato fields. The same training and test pixels were equally applied to the two multi-temporal classification schemes. For the comparison, we also classified each of two TM images separately.

\section{RESULTS AND DISCUSSIONS}

Although there are eight land cover classes including wheat and potato, we are mainly interested in classification of crop lands. Potato fields are classified into two classes of early potato and late potato and then merged together after the classification. Table 1 shows the classification accuracies of wheat, potatoes, crop (combined wheat and potato), and overall of eight classes for the two multi-temporal classifications and two classifications using a single TM image only. As expected, the crop classification accuracy is higher with multi-temporal classification than with the classifications using a single TM image of either July or August.

When we used only the TM image of July, crop classification has relatively low accuracy (70.6\%). In July wheat has about the maximum leaf growth and, therefore, its spectral characteristics are similar to nearby forest and grassland. Because of that, the wheat 
Table 1. Classification accuracies of wheat, potatoes, crop (combined wheat and potato), and overall eight land cover classes from the four different classifications applied in this study

$(\%)$

\begin{tabular}{c|c|c|c|c|c}
\hline \hline \multicolumn{2}{c|}{ Class } & $\begin{array}{c}\text { Classification on combined } \\
\mathrm{TM}_{\text {July }} \text { and } \mathrm{TM}_{\text {Aug }}\end{array}$ & $\begin{array}{c}\text { Layered classification } \\
\text { using } \mathrm{TM}_{\text {July }} \text { and } \mathrm{TM}_{\text {Aug }}\end{array}$ & $\begin{array}{c}\text { Classification using } \\
\mathrm{TM}_{\text {July }} \text { only }\end{array}$ & $\begin{array}{c}\text { Classification using } \\
\mathrm{TM}_{\text {Aug }} \text { only }\end{array}$ \\
\hline \multirow{2}{*}{ potato } & wheat & 77.9 & 90.3 & 61.8 & 91.2 \\
\cline { 2 - 6 } & early potato & 83.7 & 98.4 & 68.6 & 55.8 \\
\cline { 2 - 6 } & late potato & 99.5 & 95.7 & 80.8 & 92.3 \\
\cline { 2 - 6 } crop (wheat+potato) & 94.9 & 96.3 & 77.2 & 81.6 \\
\hline \multicolumn{2}{c|}{ overall } & 87.7 & 93.7 & 80.6 & 89.7 \\
\hline \hline
\end{tabular}

classification accuracy is only $61.8 \%$. Early potato has also enough leaf growth in July and large portion of early potato land is misclassified into grassland. Late potato is relatively well classified with the July TM image since its growth is still premature and can be separated from other classes although it is similar to bare soil. The combined accuracy of both early potato and late potato is $77.2 \%$, which may be below the level of practical application required by the local authority. The July TM image alone provides little information for crop discrimination while the August TM image shows improved discrimination potential for crop lands. Wheat growth exceeds the maximum stage of leaf development and it is senescence before harvest. Such unique spectral characteristics of wheat field in August may be the reason for the high accuracy $(91.2 \%)$. While late potato field has maximum leaf growth in August, early potato has been already harvested or leaves turn to yellowish before harvest, which makes it difficult to separate from bare soil. From the classification results of a single TM image of either July or August, it is clear that wheat and potato cannot be correctly classified.

When we used both July and August images, the crop classification accuracies improved greatly. The highest crop classification accuracy (93.7\%) is obtained from the layered classification using both TM images of July and August. The misclassifications using a single TM image were mostly found between potato and bare soil.
The layered classification solved this problem by separating two confusing classes from the August TM image. These two classes were later classified using the July TM image without interference from other classes. The layered classification scheme provides the highest accuracy for not only crop lands but also the other land covers. The classification on the combined 12 bands of two TM images also provides relatively high crop accuracy (87.7\%). In particular, potato fields having large variation between July and August are well separated by the temporal characteristics on the combining two TM images. However, wheat accuracy is not that high. Wheat has not distinguishing temporal characteristics as compared to potatoes and is mixed with grassland and potato in the combined dataset. There are other classification approaches for classifying multi-temporal images (Choi et al., 201) that could provide better classification accuracy. In this study, we are trying to show the value of using multi-temporal images rather than recommending a certain classification method.

Although classification accuracy assessment using test samples is the most common way of measuring classification performance, it is not always the best. It can be subjective to the number, distribution, and method of selecting test samples. Therefore, it is necessary to compare classified outcome by visual interpretation. Fig. 4 compares the classified maps of four approaches applied in the study. The bare soil 


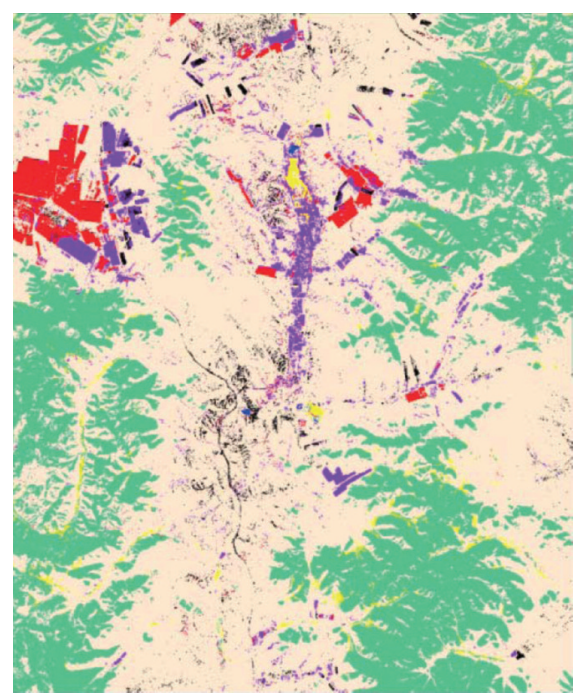

(a) Combined $\mathrm{TM}_{\text {July }}$ and $\mathrm{TM}_{\text {Aug: }}$

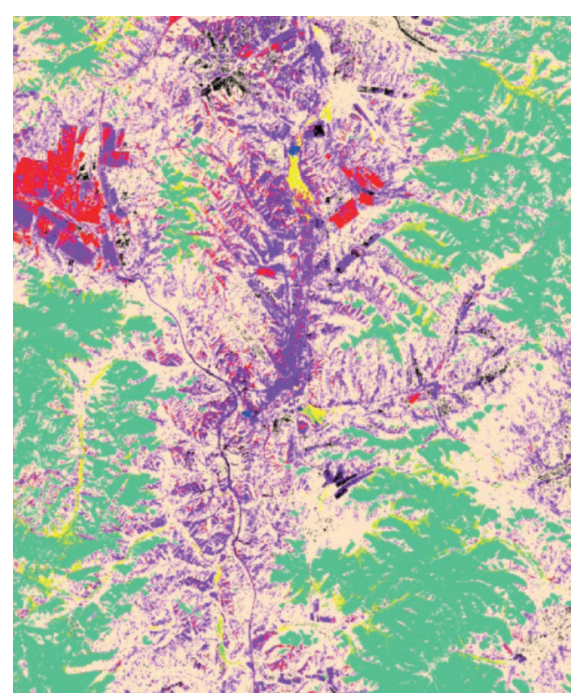

(c) $\mathrm{TM}_{\text {July }}$ only

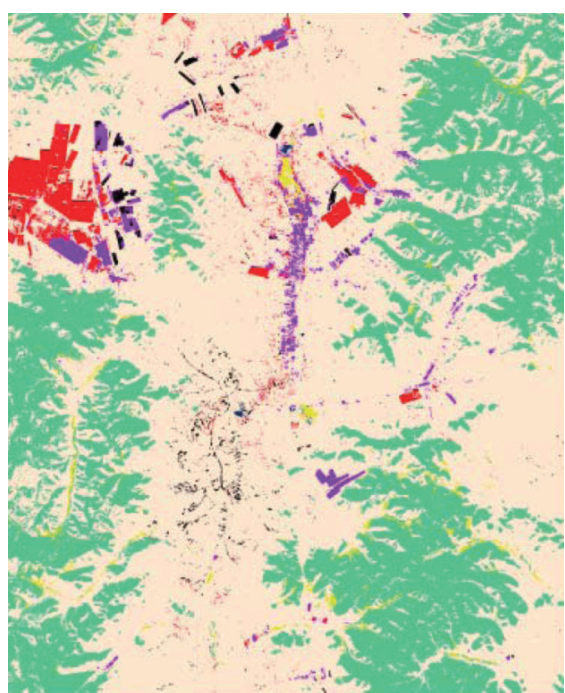

(b) Layered classification using $\mathrm{TM}_{\mathrm{July}}$ and $\mathrm{TM}_{\mathrm{Aug}}$

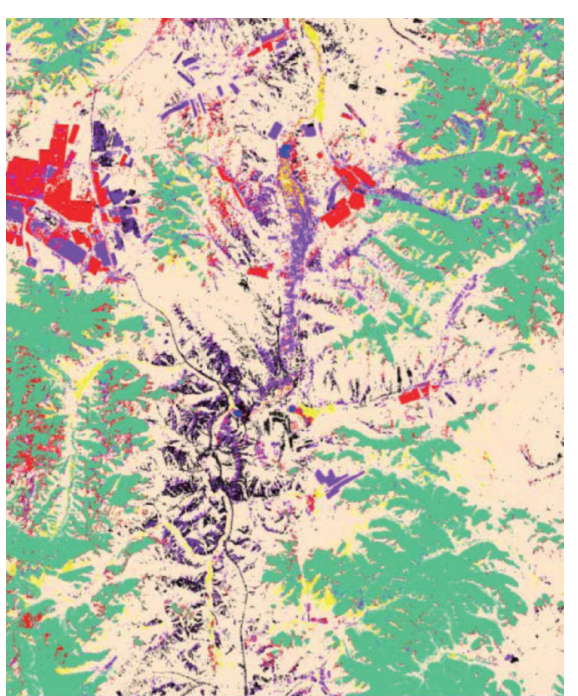

(d) $\mathrm{TM}_{\text {Aug. only }}$
Legend
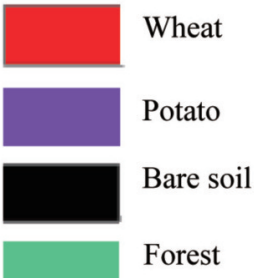

Grassland
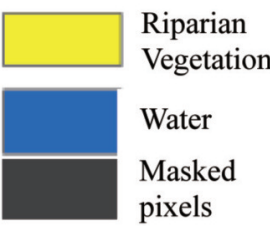

Water

Masked

pixels

Fig. 4. Crop land classification results of (a) multitemporal classification of combined $T M_{\text {July }}$ and $T M_{\text {Aug, }}$ (b) layered classification using TMuly and TMAug, (c) classification using only TMJuly, and (d) classification using only TMAug.

fields were seen with small rectangular shape in the multi-temporal classification (a, b). As mentioned before, bare soil fields were either abandoned ground after a few years of crop cultivation or fallow ground for crop rotation. They were correctly separated from the potato fields by using multi-temporal images. Although the classification accuracy of the August TM image was relatively high, the classified map (d) shows large areas of evident misclassification. In the map, wheat class has large portion of commission error from forest and grasslands. In addition, large portions of grassland were misclassified into bare soil. From the visual interpretation, it is clear that the wheat and potato fields can be correctly separated from other land covers when we use both July and August images.

\section{CONCLUSIONS}

In Mongolia, reliable agricultural statistics is a 
primary concern to solve the problem for the national plans on sustainable development. Because of harsh climate conditions, short growing season, and poor soil fertility, permanent crop lands are very limited. To solve such problems, it is necessary to have accurate map of crop lands in time. In this study, we showed that satellite remote sensing method can provide reliable information on the distribution and size of crop land in time.

In the study area of northern Mongolia, temporal variation of spectral characteristics of wheat and potato are very important to classify them. Even with relatively short time period between early July and late August, crop phenology of wheat and potato is notably different. During the short growing season in Mongolia, date of seeding, sawing, leaf growth, and harvest time varies greatly. We used two TM images of early July and late August to classify wheat and potatoes that have slightly different planting time. Classification accuracy of crop lands was much higher when we used multitemporal images as compared to the TM image of either July or August alone. Therefore, it is strongly recommended to use multi-temporal images obtained during the growing season to map small segmented crop lands in Mongolia. Although the layered classification used in this study provides the highest accuracy, it may not be the ultimate method. There could be many other approaches for classifying multitemporal images, which provide better classification accuracy. In this study, however, we are trying to suggest the value of using multi-temporal images rather than implying a certain classification method.

The multi-temporal classification scheme used in this study could be further refined. Crop cultivation in Mongolia is very site-limited. If we can define the topographic, climatic, and soil conditions that are suitable for crop cultivation, we could narrow down the potential crop lands. In such way, we do not have to classify all area to find crop lands that are very small portion as compared to other land covers. Further study is needed to define the spatial characteristics of existing crop lands and to introduce such spatial characteristics into the crop mapping over wide area.

\section{Acknowledgement}

This study was supported by the Inha University Research Fund in 2013.

\section{REFERENCES}

Batbileg, B., 2009. An effect of topographic factors on location of crop fields, Proc. of the $3^{\text {rd }}$ International and National Workshop on Applications of Geoinformatics for Mongolian Natural Resource and Environment, 175-181.

Choi, H.A., W.K. Lee, Y.W. Son, T. Kojima, and H. Muraoka, 2010. Vegetation classification using seasonal variation MODIS data, Korean Journal of Remote Sensing, 26(6):665-673.

Conese, C., and F. Maselli, 1991. Use of multi-temporal information to improve classification performance of TM scenes in complex terrain, ISPRS Journal of Photogrammetry and Remote Sensing, 46(4): 187-197.

FAO, 2011. Mongolia and FAO Achievement and success stories, http://www.fao.org/fileadmin/ templates/rap/files/epublications/ Mongoliaedoc FINAL.pdf

Foody, G.M., and A. Mathur, 2006. The use of small training sets containing mixed pixels for accurate hard image classification: Training on mixed spectral responses for classification by a SVM, Remote Sensing of Environment, 103(2): 179-189.

Jang, M.W., Y.H. Kim, N.W. Park, and S.Y. Hong, 2012. Mapping Paddy Rice Varieties Using Multi-temporal RADARSAT SAR Images, 
Korean Journal of Remote Sensing, 28(6):653660.

Jeong, S.G., C.H. Park, and S.W. Kim, 2006. Land cover classification of the Korean peninsula using linear spectral mixture analysis of MODIS multi-temporal data, Korean Journal of Remote Sensing, 22(6): 553-563.

Lanjeri, S., J. Melia, and D. Segarra, 2001. A multitemporal masking classification method for vineyard monitoring in central Spain, International Journal of Remote Sensing, 22(16): 3167-3186.

Lay, R.J., 2005. Use of Landsat TM and ETM+ to describe intra-season change in vegetation, with consideration for wildlife management, Doctoral dissertation, University of Northern British Columbia, Canada.

Maruthi Sridhar, B.B., R.K. Vincent, W.B. Clapham, S.I. Sritharan, J. Osterberg, C.M. Neale, and D.R. Watts, 2010. Mapping saltcedar (Tamarix ramosissima) and other riparian and agricultural vegetation in the lower Colorado River region using multi-spectral Landsat TM imagery, Geocarto International, 25(8): 649662.

Mulla, D.J. 2012. Twenty five years of the remote sensing in precision agriculture: Key advances and remaining knowledge gaps, Biosystems Engineering, 114(2013): 358-371.

Murthy, C.S., P.V. Raju, and K.V. Badrinath, 2003. Classification of wheat crop with multi- temporal images: performance of maximum likelihood and artificial neural networks, International Journal of Remote Sensing, 24(23): 4871-4890.

Ortiz, M.J., A.R. Formaggio, and J.C.N. Epiphanio, 1997. Classification of croplands through integration of remote sensing, GIS, and historical database, International Journal of Remote Sensing, 18(1): 95-105.

Ryu, J.H., K.S. Han, K.J. Pi, M.J. Lee, 2013. Analysis of Land Cover Change Around Desert Areas of East Asia, Korean Journal of Remote Sensing, 29(1): 105-114.

Turker, M., and M. Arikan, 2005. Sequential masking classification of multi-temporal Landsat7 ETM+ images for field-based crop mapping in Karacabey, Turkey, International Journal of Remote Sensing, 26(17): 3813-3830.

UNDP, 2012. Mongolia's Sustainable Development Agenda: progresses, bottlenecks and vision for the future, Proc. on United Nations Conference on Sustainable Development, 1-88.

Wilhelm, W.W., J.R. Hess, D.L. Karlen, J.M. Johnson, D.J. Muth, J.M. Baker, and G.E. Varvel, 2010. Review: Balancing limiting factors and economic drivers for sustainable Midwestern US agricultural residue feedstock supplies, Industrial Biotechnology, 6(5): 271-287. 